IJRMMS-D-13-00306 - edited and approved by editor

\title{
Studies on the Formation of Discontinuous Rock Fragments During Cutting Operation
}

\author{
Pradeep L. Menezes ${ }^{1 *}$, Michael R. Lovell ${ }^{1}$, Ilya V. Avdeev ${ }^{2}$ and C. Fred Higgs III ${ }^{3}$ \\ ${ }^{1}$ Department of Industrial Engineering, University of Wisconsin-Milwaukee, Milwaukee, Wisc, \\ USA \\ ${ }^{2}$ Department of Mechanical Engineering, University of Wisconsin-Milwaukee, Milwaukee, Wisc, \\ USA \\ ${ }^{3}$ Department of Mechanical Engineering, Carnegie Mellon University, Pittsburgh, Penn, USA
}

\begin{abstract}
A rock fragmentation process is simulated during mechanical cutting of rock using an explicit finite element code, LS-DYNA. In the simulation, a cutting tool is orthogonally moved against stationary rock materials made of sandstone and limestone. Rock material properties have been incorporated using an advanced damage constitute material model. Simulations were performed for various rake angles at different cutting velocities and cutting depths. The variation of cutting forces, stresses, rock fragment morphology and the character of fragment formation have been investigated. Overall, the results indicate that the explicit FEM is a powerful tool for simulating rock cutting and the fragmentation process. More specifically, the separation of rock fragments from the base rock slab was accurately predicted using the numerical model. The cutting forces and rock fragment characteristics were strongly influenced by rake angle when compared to cutting tool velocities for a given depth of cut. This information is shown to be highly pertinent to better understanding cutting rates and tool wear.
\end{abstract}

Keywords: Rock cutting, Finite element modeling, Rock fragment, Cutting forces.

\footnotetext{
* Corresponding author - $\underline{\text { menezesp @uwm.edu }}$
} 


\section{Introduction}

As the oil and gas industries attempt to drill for reserves at greater depths, it is extremely important to better understand the tribological interactions between the cutting tool and the embedded rock. This is because reaching deep oil and gas reserves requires the continual cutting of rock at extremely high pressure and high temperature (HPHT) conditions. Decreased penetration rates in deep HPHT drilling has been identified by many drilling experts as one of the most important factors threatening the future of the deep gas drilling market. There is a significant demand for improvement in rock drilling technology to accomplish higher penetration rates and longer tool life, which depends to a large degree on the understanding of the tool-rock cutting process.

Many experimental investigations have contributed to a better understanding for the rock-tool interaction, tool wear, and thermal behavior during cutting using a PDC (Polycrystalline Diamond Compact) cutting tool [1-5]. Since experiments are usually costly to run and it is difficult to directly observe the rock fragmentation removal process, numerical simulations have been performed to elucidate rock-tool interaction during rock cutting. Various numerical models such as the Finite Difference Method (FDM) [6-11], the Finite Element Method (FEM) [12-32], the Discrete Element Method (DEM) [33-36], and the Boundary Element Method (BEM) [37, 38] have been employed in the past for modeling of rock-tool interaction problems. McKinnon and Barra [7] performed numerical investigations using FDM. The authors [7] incorporated Fast Lagrangian Analysis of Continuum (FLAC) code in the FDM to study the relationships between fracture initiation, growth, stress field and boundary conditions. It was found that the fracture development in a region undergoing deformation may vary significantly depending on whether the boundaries were confined or unconfined. No chip formation was detected using this numerical code. Kou et al. [20] simulated the failure process of rock cutting by using two-dimensional plane strain Rock Failure Process Analysis (RFPA) which is a simple FEM code. This model qualitatively predicted the considerable damage occurring locally, under and ahead of the cutter, the dipping tensile fractures that were the characteristic damage signature. The model also predicted the development of variously shaped chips ahead of the cutter. However, it can be believed that there will be a major problem for adopting RFPA in rock cutting simulation as the failed elements 
were not really separated from the intact elements and after a larger strain the method will fail to work. Although, RFPA model appears to be an attractive and simple means but is limited to only in the investigation of initial failure mechanism. Cho et al. [31, 32] studied the rock fragmentation process using explicit finite element code, AUTODYN3D. In these simulations, cut rock volumes were determined by use of an erosion option that was available in the simulation code whereby rock elements that reached tensile failure level during simulation were immediately eliminated. Cut rock volumes were simply calculated from the removed (eroded) mass during modeling. Huang and Detournay [35] studied the rock-tool interaction using DEM (2D) with Particle Flow Code (PFC) to analyze failure mechanisms in indentation and cutting of rocks. The authors concluded that the rock fragments can be simulated using the DEM. Tan et al. [37] used a DDM (Displacement Discontinuity Method) which is an indirect BEM to simulate cracks and chips formation process by indentation tools. The results showed that chips were formed by multiple mechanisms of either tension or shear, or their combinations. However, chip separation was not detected in this study.

In this study, rock-cutting simulations were performed using an explicit FEM approach as it is more advanced and versatile than the other methods. The most important feature of the FEM is that the chip formation mechanism can be studied at the micro level. The FEM can also provide detailed information on the distribution of temperature, stresses, strains and strain-rates in the chip formation zone. In earlier efforts [17-20], chip formation has been investigated using FEM technique. The chipped rock fragments, however, were not separated from the work-piece because of the limitation of the numerical method. In addition, most of these simulations are either "in-house" codes or with subroutines, which significantly limit their availability to the engineering community. Thus, in the present investigation, chip fragmentation process was studied using commercially available FEM code, LS-DYNA. The simulations were carried out for a wide range of rake angles, depths of cut, and cutting velocities. The cutting forces, distribution of stresses and morphology of discontinuous rock fragments separated from the base rock have been studied.

\section{Material and Methods}


All simulations were performed using an explicit non-linear finite element code, LS-DYNA. In the simulations, a tool and a base rock slab were considered for modeling. The base rock slab was modeled as a rectangular block of $50 \mathrm{~mm}$ in length and $20 \mathrm{~mm}$ in height. Two-dimensional quadrilateral elements were implemented for both the cutting tool and base rock. A mesh of 9,550 nodes and 9,201 elements were used. The displacement boundary conditions applied to the finite element model were as follows: (a) the bottom nodes of the base rock slab were fully constrained in $X-, Y$-, and $Z$ directions, (b) the base rock slab was constrained in the Z-direction and (c) the cutting tool was constrained in the $Y Z$ plane. The cutting tool had a rake angle, $\alpha$, of $+15^{\circ}, 0^{\circ}$ and $-15^{\circ}$. The relief angle of the cutting tool was $15^{\circ}$. The cutting tool was moved against the stationary base rock slab at sliding velocities, $v$, of $0.1,1,4,10,50$ and $100 \mathrm{~mm} / \mathrm{s}$ in the horizontal direction. These velocities were specifically chosen as similar range of cutter velocities has been utilized for rock cutting process $[39,40]$. For a given sliding velocity, the simulation was performed for depths of cut (d) of 1, 2, 3 and $4 \mathrm{~mm}$. The deformation of the cutting tool was assumed to be negligible compared to the base rock slab. Material type RIGID_20 [41] was assigned to the cutting tool and the Damage constitutive law material type MAT_105 [41] was used for the base rock slab. The damage constitutive law adopted in the models allows the defining of advanced parameters for the tool's penetration into the base rock slab and for the fragmentation of the rock. The material properties assigned for the cutting tool and the base rock slab are presented in Table 1. Two types of rock materials, sandstone and limestone, were considered in the present investigation. The cutting tool and the base rock slab contact interface was simulated using automatic two-dimensional node to surface contact. The friction factors (static and dynamic) are assumed to be 0 (friction less sliding) in the contact model.

It is well known that at the initial stage of rock cutting, intense crushing of the rock occurs and only then as cutting progresses cracks generated at a certain depth in the rock, leading to the formation of rock fragment. The formation of rock fragments is one of greatest interests, since precisely at this stage the maximum effectiveness of fracturing is achieved [43]. To predict both the initiation of a fracture (location, size) and further propagation of the crack (growth path), it is necessary to know in detail the stress field, which is highly dependent on the material model performance. Thus, one of the biggest 
challenges associated with modeling the behavior of rock cutting is the difficulty of incorporating a realistic material model that can accurately represent the physical system. The material damage model incorporated in the material database library of LS-DYNA has the ability to separate rock fragments from the base rock. Hence, in the present investigation, the damage material model is considered.

In LS-DYNA, the MAT_105 damage model [41], incorporated in the material library, is basically an elastic visco-plastic material model combined with the continuum damage mechanics (CDM). The CDM model was proposed by Lemaitre [44]. The effective stress, $\bar{\sigma}$, which is the stress calculated over the section that effectively resists the forces can be related to the damage variable $(D)$ and stress tensor $(\sigma)$ and is defined by

$$
\bar{\sigma}=\frac{\sigma}{1-D}
$$

The evolution equation for the damage variable is defined as

$$
\dot{D}= \begin{cases}\frac{Y}{S(1-D)} \dot{r} & \text { for } r>r_{D} \text { and } \sigma_{1}>0 \\ 0 & \text { for } r \leq r_{D}\end{cases}
$$

where $r_{D}$ is the damage threshold, $\dot{r}$ is damage governed by plasticity, $S$ is a damage strength, $Y$ is the damage strain energy release rate, and $\sigma_{1}$ is the maximum principal stress. The damage strain energy release rate $(Y)$ is given by

$$
Y=\frac{\sigma_{v m}^{2} R_{v}}{2 E(1-D)^{2}}
$$

where $\sigma_{v m}$ is the equivalent von Mises stress, and $E$ is the Young's Modulus. The triaxiality function $R_{v}$ is defined as

$$
R_{v}=\frac{2}{3}(1+v)+3(1-2 v)\left(\frac{\sigma_{H}}{\sigma_{v m}}\right)^{2}
$$

where $\sigma_{H}$ is the hydrostatic stress, and $v$ is the Poisson's ratio

The uniaxial stress-strain curve is given in the following form 


$$
\sigma\left(r, \dot{\varepsilon}_{\mathrm{eff}}^{\mathrm{p}}\right)=\sigma_{0}+Q_{1}\left(1-e^{\left(-C_{1} r\right)}\right)+Q_{2}\left(1-e^{\left(-C_{2} r\right)}\right)+V_{k}\left(\dot{\varepsilon}_{\mathrm{eff}}^{\mathrm{p}}\right)^{V_{m}}
$$

where $\varepsilon_{\text {eff }}^{p}$ is the effective viscoplastic strain. In Eq. (5), the damage accumulated plastic strain $(r)$ can be calculated using the equation

$$
\ddot{r}=\dot{\varepsilon}_{\mathrm{eff}}^{\mathrm{p}}(1-D) \ldots \ldots(6)
$$

For bricks, the following yield criteria is used

$$
\sigma\left(r, \dot{\boldsymbol{\varepsilon}}_{\mathrm{eff}}^{\mathrm{p}}\right)=\frac{1}{2}\left[\left(\bar{\sigma}_{22}-\bar{\sigma}_{33}\right)^{2}+\left(\bar{\sigma}_{33}-\bar{\sigma}_{11}\right)^{2}+\left(\bar{\sigma}_{11}-\bar{\sigma}_{22}\right)^{2}\right]+3\left(\bar{\sigma}_{23}{ }^{2}+\bar{\sigma}_{31}{ }^{2}+\bar{\sigma}_{12}{ }^{2}\right)
$$

The damage materials model, MAT_105, treats strain rate using the Cowper and Symonds model which scales the yield stress with the factor

$$
\sigma_{y}=\left[1+\left(\frac{\dot{\varepsilon}}{C}\right)^{\frac{1}{p}}\right] \sigma_{0}
$$

where $\sigma_{0}$ is the initial yield stress, $\dot{\varepsilon}$ is the strain rate, $C$ and $P$ are Cowper- Symonds strain rate parameters. To convert these constants, set the viscoelastic constants, $V_{k}$ and $V_{m}$, to the following values:

$$
\begin{gathered}
V_{k}=\sigma\left(\frac{1}{C}\right)^{\frac{1}{p}} \\
V_{m}=\frac{1}{p} \ldots .
\end{gathered}
$$

Only parameters that control the elastic-perfectly plastic response of damage material model were setup in the input. In addition, damage parameters were defined such that the performance of the rock cutting simulations appeared reasonable and the mechanisms involved were very close to the reality. Table 2 lists the input damage parameters used for MAT_105. The damage parameters defined in the material model play an important role in the formation of rock fragmentation process. When the failure criterion is reached, the stress components are set to zero and remain zero for the rest of the simulation. After one element fails, it will be removed from the calculation cycle and 
a crack will initiate and propagate within the material. The specific rock fragment will, therefore, depend on the deformation state of material elements, which are determined by the combined effects of work-piece properties, cutting speeds, and tool geometries.

\section{Results and Discussion}

\subsection{Effect of positive $\left(+15^{\circ}\right)$ rake angle}

Figure 1(a) shows the numerically computed stress distributions (von Mises stresses) obtained in the sandstone rock slab for a rake angle of $+15^{\circ}$, cutting depth of 1 $\mathrm{mm}$, and rock cutting velocity of $100 \mathrm{~mm} / \mathrm{s}$. In the figure, it is found that the maximum effective stress was located at the leading edge of the cutting tool. Small rock fragments begin to form and then separate out from the base rock slab ahead of the tool. It is important to note that the interactions between the separated rock fragments and the base rock slab is not defined, therefore, the rock fragments and base rock slab have no actual interactions after separation. Numerical values of cutting forces were also computed during simulation. The variation of cutting forces with distance obtained for this simulation is presented in Fig. 1(b). The average cutting forces for a distance of $50 \mathrm{~mm}$ was found to be $\approx 0.1 \mathrm{kN}$.

Rock cutting simulations were also performed at various depths of cut and cutter velocities. Figures 2(a) and 2(b) show the stress distributions obtained in the sandstone rock slab for cutter velocities of $0.1 \mathrm{~mm} / \mathrm{s}$ and $100 \mathrm{~mm} / \mathrm{s}$, respectively. The simulations were performed for a rake angle of $+15^{\circ}$ at a cutting depth of $3 \mathrm{~mm}$. Comparing figures 2(a) and 2(b) it can be noticed that the size of the rock fragments depended on the velocity of the cutter. More specifically, the size of the rock fragments decreased with increasing cutting velocity due to strain hardening of the rock slab. As regards to the formation of rock fragments at various depths of cut, it can be observed by comparing Fig. 1(a) and 2(b) that the size and morphology of the rock fragments considerably depended on the depths of cut. More specifically, the size of the rock fragment was increased by increasing the depth of cut. Numerical values of cutting forces were computed during simulation. As shown in Fig. 3, the cutting force does not vary much with cutter velocity, particularly at lower velocities (Fig. 3(a)). The influence of cutter velocity on cutting forces is substantial only at higher velocities (Fig. 3(a)). In addition, 
the cutting tool velocity had a significant effect on cutting forces at larger depths of cut. It can be seen that the cutting forces increases with increasing depth of cut (Fig. 3(b)). More specifically, a linear relationship between the cutting forces and the depth of cut can be observed for a given cutter velocity (Fig. 3(b)). It can also be observed that the variation in cutting forces increases with increasing both velocities and depths of cut (Fig. 3(b)).

\subsection{Effect of $0^{\circ}$ rake angle:}

A similar procedure to that explained above was adopted when cutting simulations of sandstone rock slab performed at $0^{\circ}$ rake angle. Figure 4 presents the stress distributions obtained in the sandstone rock slab for a rake angle of $0^{\circ}$, cutting depth of 1 $\mathrm{mm}$, and cutting velocity of $100 \mathrm{~mm} / \mathrm{s}$. Like $+15^{\circ}$ rake angle, the maximum effective stress was located at the leading edge of the cutting tool. Small rock fragments form and then separate out from the base rock slab ahead of the tool. It is interesting to note that a few fine rock fragments were also escaped below the cutting tool in a direction opposite to the cutting direction. Such observations were not found for $+15^{\circ}$ rake angle. The movement of rock fragments in front of the cutting tool becomes difficult and hence the movement of rock fragments below the cutting tool begins when rake angle changed from $+15^{\circ}$ to $0^{\circ}$. The morphology of the rock fragments was also significantly altered when the rake angle was changed from $+15^{\circ}$ (Fig. 1(a)) to $0^{\circ}$ (Fig. 4) under identical operating conditions. The size of the rock fragments were less for the rake angle of $0^{\circ}$ (Fig. 4) when compared to $+15^{\circ}$ (Fig. 1(a)). As regards to the simulations performed at various depths of cut and cutter velocities, Fig. 5(a) and 5(b) show the stress distributions observed in the sandstone rock slab for cutter velocity of $0.1 \mathrm{~mm} / \mathrm{s}$ and $100 \mathrm{~mm} / \mathrm{s}$, respectively. The simulations were performed for a rake angle of $0^{\circ}$ at a cutting depth of $3 \mathrm{~mm}$. It can be seen that the size of the rock fragments decreased with increasing cutting velocity (comparing Fig. 5(a) and 5(b)) and the size of the rock fragment was increased by increasing the depth of cut (comparing Fig. 4 and 5(b)) as observed for $+15^{\circ}$ rake angle. Figure 6 shows the variation of average cutting forces for various velocities and depths of cut. Akin to $+15^{\circ}$ rake angle, the cutting tool velocity had a significant effect on

cutting forces, particularly at higher velocities (Fig. 6(a)) and the cutting forces were 
found to increase with increasing depth of cut (Fig. 6(b)). In contrast to $+15^{\circ}$ rake angle, here, the mean cutting force tends to be lower than the predicted by the linear relationship as the depth of cut increases. Like $+15^{\circ}$ rake angle, the variation in cutting forces was found to increase with increasing both velocities and depths of cut (Fig. 6(b)). Comparing $+15^{\circ}$ and $0^{\circ}$ rake angles, it can be seen that the mean cutting forces are depended on rake angles. More specifically, the cutting forces were more for the rake angle of $0^{\circ}$ (Fig. 6(b)) when compared to $+15^{\circ}$ (Fig. 3(b)) for a given operating conditions.

\subsection{Effect of Negative $\left(-15^{\circ}\right)$ rake angle}

As regards to the cutting simulations of sandstone rock performed at $-15^{\circ}$ rake angle, Fig. 7 shows the stress distributions obtained in the base rock slab for a cutting depth of $1 \mathrm{~mm}$ and cutter velocity of $100 \mathrm{~mm} / \mathrm{s}$. Similar to the rake angles of $+15^{\circ}$ and $0^{\circ}$, the maximum effective stress was observed at the leading edge of the cutting tool. Also, fine rock fragments form and then separate out from the base rock slab ahead of the cutting tool. Like $0^{\circ}$ rake angle, few fine rock fragments were escaped below the cutting tool in a direction opposite to the cutting direction. The intensity of these rock fragments were found to be more for $-15^{\circ}$ rake angle when compared to $0^{\circ}$ rake angle. The movement of rock fragments in front of the cutting tool becomes further difficult and hence the escape of rock fragments below the cutting tool increases when rake angle changed from $0^{\circ}$ to $-15^{\circ}$. The morphology of the rock fragment, again, was significantly different when compared to $+15^{\circ}$ (Fig. 1(a)) and $0^{\circ}$ rake angles (Fig. 4) under identical simulation conditions. The size of the rock fragment was less for the rake angle of $-15^{\circ}$ (Fig. 7) when compared to $0^{\circ}$ (Fig. 4). For this rake angle, the simulations were also performed at various velocities and depths of cut. Figures 8(a) and 8(b) show the stress distributions observed in the base rock slab for cutter velocity of $0.1 \mathrm{~mm} / \mathrm{s}$ and $100 \mathrm{~mm} / \mathrm{s}$, respectively. The simulations were performed for a rake angle of $-15^{\circ}$ at a cutting depth of $3 \mathrm{~mm}$. It can be seen that the size of the rock fragments decreased with increasing cutting velocity (comparing the Fig. 8(a) and 8(b)) and the size of the rock fragment was increased by increasing the depth of cut (comparing Fig. 7 and 8(b)) as observed for $+15^{\circ}$ and $0^{\circ}$ rake angles. It is important to note that among the three rake angles, the size of the rock fragment was greatest for the $+15^{\circ}$ rake angle (Fig. 1(a)), followed by $0^{\circ}$ (Fig. 4), 
and was the least for $-15^{\circ}$ (Fig. 7) rake angle. Identical trends were found for simulations performed at different velocities and depths of cut under a given operating conditions. In general, it was noticed that the rock fragment size depended on the velocity of the cutter. More specifically, the size of rock fragment decreased with increasing cutter velocity. The size of the rock fragment was increased by increasing the depth of cut. Thus, it can be inferred from this study that the formation of rock fragments was strongly influenced by the rake angle, depth of cut, and cutting velocity during rock cutting. Figure 9 shows the variation of average cutting forces for various velocities and depths of cut. Like $+15^{\circ}$ and $0^{\circ}$ rake angles, the cutting tool velocity had a significant effect on cutting forces only at higher velocities (Fig. 9(a)) and the cutting forces were found to increase with increasing depth of cut (Fig. 9(b)). Similar to $0^{\circ}$ rake angle, the mean cutting force did not vary linearly with depth of cut. Like $+15^{\circ}$ and $0^{\circ}$ rake angles, the variation in cutting forces was found to increase with increasing both velocities and depths of cut (Fig. 9(b)). Comparing $0^{\circ}$ and $-15^{\circ}$ rake angles, the mean cutting forces were found to be more for the rake angle of $-15^{\circ}$ (Fig. 9(b)) than $0^{\circ}$ (Fig. 6(b)) for a given operating conditions.

\subsection{Influence of rock material}

Cutting simulations were also performed using limestone rock slab at three rake angles $\left(\alpha=+15^{\circ}, 0^{\circ}\right.$ and $\left.-15^{\circ}\right)$, four depths of cut $(d=1,2,3,4 \mathrm{~mm})$ and six velocities $(v$ $=0.1,1,4,10,50$ and $100 \mathrm{~mm} / \mathrm{s}$ ) under identical operating conditions. Figure 10 shows cutting simulation of limestone rock slab for three rake angles for a cutting depth of 1 $\mathrm{mm}$ and cutting velocity of $100 \mathrm{~mm} / \mathrm{s}$. Like sandstone case, the maximum effective stress was observed at the leading edge of the cutting tool. Fine rock fragments form and then separate out from the base rock slab ahead of the tool (Fig 10(a)-(c)). For $0^{\circ}$ and $-15^{\circ}$ rake angles, few small rock fragments were escaped below the cutting tool in a direction opposite to the cutting direction and the intensity of these small rock fragments was more for $-15^{\circ}$ rake angle when compared to $0^{\circ}$ rake angle (compare Fig 10(b) and (c)). The morphology of the rock fragments was significantly different for different rake angles. Among the three rake angles, the size of the rock fragment was greatest for the $+15^{\circ}$ rake angle, followed by $0^{\circ}$, and was the least for $-15^{\circ}$ rake angle. It was also observed that the size of the rock fragments decreased with increasing cutting velocity 
and the size of the rock fragment was increased by increasing the depth of cut for a given operating conditions. The size of the rock fragments was almost the same for both sandstone and limestone rock materials for a given operating conditions. As regards to the cutting forces, Fig. 11 shows the variation of cutting forces with depths of cut at different cutting velocities when simulations were performed using limestone rock slab. It can be seen that the cutting forces increases with increasing depth of cut. For $+15^{\circ}$ rake angle, a linear relationship between the cutting forces and the depth of cut was observed (Fig. 11(a)). However, such linear relationship was not observed for $-15^{\circ}$ and $0^{\circ}$ rake angles (Figs. 11(b) and (c)). The influence of cutter velocity on cutting forces was substantial only at higher velocities. The mean cutting forces were found to be highest for the $-15^{\circ}$ rake angle followed by $0^{\circ}$ and least for $+15^{\circ}$ rake angle. The mean cutting forces are comparatively larger for limestone rock material when compared to sandstone rock material due to higher strength values.

The rake angle had a significant effect on cutting forces for a given velocity and depth of cut. It was observed that among the three rake angles, the average cutting force was highest for the $-15^{\circ}$ rake angle, followed by $0^{\circ}$, and was the least for $+15^{\circ}$ for both rock materials. Identical trends were found for simulations performed at different velocities and depths of cut. The cutting forces vary with rake angle because positive rake angles reduce compression, cutting forces, and therefore yield a less deformed chip. Negative rake angles, in contrast, increase compression and cutting forces, which yields a highly deformed chip.

The cutting forces did not vary much with velocity up to $10 \mathrm{~mm} / \mathrm{s}$ for a given rake angle. The influence of cutter velocity on cutting forces was significant only at higher velocities and greater cutting depths. The influence of cutter velocity on cutting forces was substantial when rake angle changed from $+15^{\circ}$ to $0^{\circ}$ and then to $-15^{\circ}$. Considering cutting velocity, the rate of deformation of the base rock slab substantially increases at the higher velocities, which leads to strain hardening along the cutting plane. The strainhardened material offers more resistance to the cutting tool, and hence increases the required cutting forces.

The cutting forces and size of the rock fragments increases with increasing depth of cut. During cutting at greater depths, it was observed that a localized plastic 
deformation zone first forms in front of the cutting tool and above the cutting edge. Then, an internal crack initiates and extends to the free surface after the material reaches the failure strain. The material then shears strongly along the crack surface and form a discontinuous rock fragment that separates along the rake face of the cutting tool.

In the literature, the propagation of a tensile crack has been proposed to explain the formation of rock fragments [45, 46]. Chaput [47] performed rock cutting experiments using sandstones and limestones. The author [47] concluded that tensile cracks initiate close to the cutter tip, then propagate into the rock material and eventually reach the free surface, thus creating rock fragment. Several numerical simulations [48, 49] model the propagation of a tensile crack from the tip of the cutting tool. Based on observations of photoelastic experiments, Minh [50] followed a qualitative elasto-brittle approach by introducing a Griffith criterion for the initiation of a tensile crack. The author [50] concluded that the tensile mode is more dominant for a negative rake angle compared to a positive rake angle.

The simulation results obtained in the present investigation were also compared with the experimental results. In the literature, Verhoef [51] reported that the cutting speed is found to have a little influence on the cutting forces except at large cutting velocities where cutting forces start to increase with the cutting velocity. Wei et al. [52] conducted experiments to study the fracture mechanism of rock cutting using various tool rake angles (positive, zero and negative). The authors reported that the size of the crushing zone is affected by the rake angle of the cutting tool and thus the chip size. It was also observed that the size of the chip increases with increasing depth of cut. The authors [52] hypothesized that the propagation of tensile crack caused the formation of rock chip. Richard [53] conducted rock cutting experiments at various depths of cut and found a linear relationship between the cutting forces and the depth of cut when depth of cut is very small. As the depth of cut increases, the mean cutting force tends to be lower than the predicted by the linear relationship. As regards to the rake angle, the experiments were conducted for rake angels from $+5^{\circ}$ to $+75^{\circ}$. It was observed that the cutting force decreased continuously with increasing rake angles. Kaitkay and Le [54] conducted experiments using various rake angles and depth of cut. The authors reported that the cutting forces were found to increase with increasing negative rake angle and depths of 
cut. A similar observation was also made by Garcia-Gavito [55] who reported that the cutting forces and rock chip size generated increase as the depth of cut increases. In addition, the cutting forces were found to increase with increasing negative rake angles. The experimental results presented in the literature [51-55] were found to be in accordance with the present simulated results.

Examining the simulated results, it is apparent that the developed damage material model provided an ability to model the rock fragment formation in explicit FEM in rock cutting. More specifically, the damage parameters (see Table 2) defined in the material model play an important role in the formation of rock fragmentation process. These results are useful to enhance efficiency of drilling, tunneling or mining operation. The present model qualitatively predicts the considerable damage occurring locally ahead of the cutting tool. The model also predicts the development of variously shaped rock fragments ahead of the cutter. Based on the previous studies [45-50], it can be believed that the fragmentation process was caused by the propagation of tensile cracks. The numerical model accurately predicts the nature of fragment morphology and demonstrated the ability of damage material model during rock cutting. The morphology of the rock fragments is the result of deformation during rock cutting and is determined by the characteristics of the base rock slab, tool geometry, and cutting parameters. This model could be used in parametric studies to determine optimal cutter designs (such as rake angle), reducing much of the expensive and time-consuming experimental work which would otherwise have to be carried out to assess the performance of a particular cutter design. This study also focuses on the feasibility of simulating discontinuous rock fragments during rock cutting without use of any "in-house" programs or user-defined subroutines. Parametric studies and the corresponding cutting tests will be performed in the future in order to understand the influence of different parameters on rock fragmentation process.

In the present simulation, the tool is considered as rigid and tool wear is neglected. This was made in order to reduce the complexities, such as the influence of tool material properties and computational time. However, in real situation, the tools are made of cemented carbide or polycrystalline diamond materials. The tools are deformable and are also subjected to wear. The rock fragment size and morphology generated from 
the base rock play an important role as rock fragments can act as third body abrasive at the interface between the tool and rock material and hence influence the cutting rate and tool wear.

In the present research, the effect of rake angle, cutter velocity and cutting depths on the rock fragmentation process was investigated. It is important to note that the size and morphology of rock fragments and cutting forces are also influenced by rock materials properties [56]. Different rock materials behave differently under the same operating conditions. In this study, only two rock materials were considered. Although, their material properties did not vary substantially, the rock fragment size and morplology were almost the same for both sandstone and limestone rock materials for a given operating conditions. The mean cutting forces are comparatively larger for limestone rock material when compared to sandstone rock material due to higher strength values. However, when rock materials, such as Gypsum or Chert, with significant variations in mechanical properties are considered, the size and morphology of the rock fragments will be completely altered [56]. In addition, the interaction between different rock and tool materials leads to different friction coefficient at the interface. The friction

leads to undesirable effects, such as adhesion and built-up edge of rock material in front of the cutting tool [57]. This ultimately changes the rake angle of the cutting tool and thus influences the cutting forces and rock fragmentation process.

\section{Conclusions}

An explicit finite-element method (FEM) code, LS-DYNA, was used to study the formation of discontinuous rock fragments during cutting of sandstone and limestone rock slabs. In the simulations, a damage model was used to define the material properties of the base rock slab during the cutting processes. The conclusions based on numerical studies are as follows.

The FEM rock cutting simulation demonstrates the importance of having a material damage model as a mechanism for generating rock fragments. The rake angle and depths of cut had a significant influence on the cutting forces and size of rock fragment formation. Cutting tool velocity had a significant effect on cutting forces, 
especially at higher depths of cut. The mechanism of separation of rock fragments was due to the internal crack initiation and extension in front of the tool.

\section{Acknowledgements}

This project was supported by the Department of Energy under title "Predicting the Tribological Fragmentation Process when Drilling into HPHT Rocks for Oil Production Using Discrete and Continuum Methods”. 


\section{References}

[1] Karasawa H, Misawa S. Development of new PDC bits for drilling of geothermal wells - Part 1: Laboratory testing. J Energy Resour Technol 1992; 114(4): 323-331.

[2] Appl FC, Wilson CC, Lakshman I. Measurement of forces, temperatures and wear of PDC cutters in rock cutting. Wear 1993; 169(1): 9-24.

[3] Li XB, Summers DA, Rupert G, Santi P. Experimental investigation on the breakage of hard rock by the PDC cutters with combined action modes. Tunnelling and Underground Space Technology 2001; 16(2): 107-114.

[4] Kaitkay P, Lei S. Experimental study of rock cutting under external hydrostatic pressure. J Mater Process Technol 2005; 159(2): 206-213.

[5] Kuru E, Wojtanowicz AK. An experimental study of sliding friction between PDC drill cutters and rocks. Int J Rock Mech Min Sci Geomech Abstr 1995; 32(3): 277283.

[6] Huang H, Damjanac B, Detournay E. Normal wedge indentation in rocks with lateral confinement. Rock Mech Rock Engg 1998; 31(2): 81-94.

[7] McKinnon SD, Barra IG. Fracture initiation, growth and effect on the stress field: a numerical investigation. J Struct Geol 1998; 20(12): 1673-1689.

[8] Fang Z, Harrison JP. Development of a local degradation approach to the modelling of brittle fracture in heterogeneous rocks. Int J Rock Mech Min Sci 2002; 39: 443457.

[9] Fang Z, Harrison JP. Application of a local degradation model to the analysis of brittle fracture of laboratory scale rock specimens under triaxial conditions. Int $\mathbf{J}$ Rock Mech Min Sci 2002; 39: 459-476.

[10] Innaurato N, Oggeri C, Oreste PP, Vinai R. Experimental and numerical studies on rock breaking with TBM tools under high stress confinement. Rock Mech Rock Engg 2007; 40 (5): 429-451.

[11] Stavropoulou M. Modeling of small-diameter rotary drilling tests on marbles. Int J Rock Mech Min Sci 2006; 43(7): 1034-1051.

[12] Tan XC, Lindqvist P-A, Kou SQ. Application of a splitting fracture model to the simulation of rock indentation subsurface fractures. Int $\mathbf{J}$ Numer Anal Meth Geomech 1997; 21: 1-13. 
[13] Tang C. Numerical simulation of progressive failure and associated seismicity. Int J Rock Mech Min Sci 1997; 34(2): 249-261.

[14] Tang CA, Fu YF, Kou SQ, Lindqvist P-A. Numerical simulation of loading inhomogeneous rocks. Int J Rock Mech Min Sci 1998; 35(7): 1001-1007.

[15] Kou SQ, Liu HY, Lindqvist P-A, Tang CA. Rock fragmentation mechanisms induced by drill bit. Int J Rock Mech Min Sci 2004; 41(3): 1-6.

[16] Liu HY, Kou SQ, Lindqvist P-A, Tang CA. Numerical simulation of shear fracture (mode II) in heterogeneous brittle rock. Int J Rock Mech Min Sci 2004; 41(3): 1-6.

[17]Liu HY, Kou SQ, Lindqvist P-A, Tang CA. Numerical simulation of the rock fragmentation process induced by indenters. Int J Rock Mech Min Sci 2002; 39: 491505.

[18] Kou SQ, Liu HY, Lindqvist P-A, Tang CA, Xu XH. Numerical investigation of particle breakage as applied to mechanical, crushing - Part II: Interparticle breakage. Int J Rock Mech Min Sci 2001; 38: 1163-1172.

[19] Tang CA, Xu XH, Kou SQ, Lindqvist P-A, Liu HY. Numerical investigation of particle breakage as applied to mechanical crushing - Part I: Single-particle breakage. Int J Rock Mech Min Sci 2001; 38: 1147-1162.

[20] Kou SQ, Lindqvist P-A, Tang CA, Xu XH. Numerical simulation of the cutting of inhomogeneous rocks. Int J Rock Mech Min Sci 1999; 36: 711-717.

[21]Zhu WC, Tang CA. Micromechanical model for simulating the fracture process of rock. Rock Mech Rock Engg 2004; 37(1): 25-56.

[22] Menezes PL, Lovell MR, Higgs CF III. Studies on the formation of discontinues rock fragments during drilling and cutting operations. STLE Annual Meeting \& Exhibition 2010; Las Vegas, USA

[23] Menezes PL, Lovell MR, Lin J-S, Higgs CF III. Finite element modeling of discontinuous chip formation during rock cutting. ASME/STLE International Joint Tribology Conference 2009; Tennessee, USA, 2009, 463-465

[24] Menezes PL, Lovell MR, Avdeev IV, Lin J-S, Higgs CF III. Studies on the formation of discontinuous chips during rock cutting using an explicit finite element model. Int J Adv Manuf Technol 2014; 70: 635-648. 
[25] Tang CA, Liu H, Lee PKK, Tsui Y, Tham LG. Numerical studies of the influence of microstructure on rock failure in uniaxial compression - Part I: Effect of heterogeneity. Int J Rock Mech Min Sci 2000; 37: 555-569.

[26] Tang CA, Tham LG, Lee PKK, Tsui Y, Liu H. Numerical studies of the influence of microstructure on rock failure in uniaxial compression - Part II: Constraint, slenderness and size effect. Int J Rock Mech Min Sci 2000; 37: 571-583.

[27] Liu HY, Kou SQ, Lindqvist P-A. Numerical studies on bit-rock fragmentation mechanisms. Int J Geomech 2008; 8(1): 45-67.

[28] Rouabhi A, Tijani M, Moser P, Goetz D. Continuum modelling of dynamic behaviour and fragmentation of quasi-brittle materials: Application to rock fragmentation by blasting. Int J Numer Anal Meth Geomech 2005; 29: 729-749.

[29] Yu B. Numerical simulation of continuous minor rock cutting process. PhD Thesis, West Virginia University, 2004, USA.

[30] Finzi AE, Lavagna M, Rocchitelli G. A drill-soil system modelization for future mars exploration. Planetary and Space Science 2004; 52(1-3): 83-89.

[31] Cho J-W, Jeon S, Yu S-H, Chang S-H. Optimum spacing of TBM disc cutters: A numerical simulation using the three-dimensional dynamic fracturing method. Tunnelling and Underground Space Technology 2010; 25(3): 230-244

[32] Cho J-W, Jeon S, Jeong H-Y, Chang S-H. Evaluation of cutting efficiency during TBM disc cutter excavation within a Korean granitic rock using linear-cuttingmachine testing and photogrammetric measurement. Tunnelling and Underground Space Technology 2013; 35: 37-54

[33] Lei S, Kaitkay P, Shen X. Simulation of rock cutting using distinct element method PFC ${ }^{2 D}$, In: Shimizu Y, Hart R, Cundall P, editors. Numerical modeling in micromechanics via particle methods 2004; 1(4): 63-72.

[34]Rojek J. Discrete element modeling of rock cutting. Comp Meth Mater Sci 2007; 7(2): 224-230.

[35] Huang $\mathrm{H}$, Detournay E. Intrinsic length scales in tool-rock interaction. Int $\mathbf{J}$ Geomech 2008; 8(1): 39-44. 
[36] Onate E, Rojek J. Combination of discrete element and finite element methods for dynamic analysis of geomechanics problems. Comput Meth Appl Mech Eng 2004; 193: 3087-3128.

[37] Tan XC, Kou SQ, Lindqvist P-A. Application of the DDM and fracture mechanics model on the simulation of rock breakage by mechanical tools. Engineering Geology 1998; 49: 277-284.

[38] Chen C-S, Pan E, Amadei, B. Fracture mechanics analysis of cracked discs of anisotropic rock using the boundary element method. Int J Rock Mech Min Sci 1998; 35(2): 195-218.

[39] Holt RM, Kjølaas J, Larsen I, Li L, Pillitteri AG, Sønstebø EF. Comparison between controlled laboratory experiments and discrete particle simulations of the mechanical behaviour of rock. International Journal of Rock Mechanics and Mining Sciences 2005; 42 (7-8): 985-995.

[40] Su O, Akcin NA. Numerical simulation of rock cutting using the discrete element method. International Journal of Rock Mechanics and Mining Sciences 2011; 48(3): $434-442$

[41]Hallquist JO. LS-DYNA Theory Manual. Livermore Software technology Corporation 2006, USA.

[42]Fjaer E, Holt RM, Horsrud P, Raaen AM, Risnes R. Petroleum Related Rock Mechanics, Elsevier, 2008, NY.

[43] Gnuchii YB, Sveshnikov IA, Borisenko VV, Podoroga VA. Application of the finiteelement method to problems of tool penetration into rock being fractured. Strength of Materials 1987; 19(8): 1160-1165.

[44]Lemaitre J. How to use damage mechanics. Nucl Eng Des 1984; 80: 233-245.

[45] Evans I. The force required to cut coal with blunt wedges. Int J Rock Mech Min Sci Geomech Abstr 1965; 2(1): 1-12.

[46] Fowell RJ. The mechanics of rock cutting. In: Comprehensive Rock Engineering. Hudson JA, editor. 1993; 4(7): Pergamon Press Ltd, Oxford, 155-176.

[47] Chaput E. Observation and analysis of hard rock cutting failure mechanisms using PDC picks. M. Phil. Thesis, 1991, Imperial College, London. UK 
[48] Wawrzynek PA. Discrete modelling of crack propagation: Theoretical aspects and implementation issues in two and three dimensions. Ph.D. Thesis, 1991, Cornell University, USA

[49] Kesteren WGMV. Numerical simulations of crack bifurcation in the chip forming cutting process in rock. In: Fracture of Brittle Disordered Materials: Concrete, Rock and Ceramics, Baker G, Karihaloo B, editors. 1995; Taylor and Francis, UK, 505524.

[50] Minh N. Frictional contact in rock cutting with blunt tools, Ph.D. Thesis, 1974, Université Paris, France.

[51] Verhoef PNW. Wear of Rock Cutting Tools: Implications for the Site Investigation of Rock Dredging Projects. PhD thesis, 1997, Technical University Delft, Netherlands.

[52] Wei X, Wang CY, Yuan H, Xie ZH. Study of fracture mechanism of rock cutting, Key Eng Mater 2003; 250: 200-208.

[53] Richard T. Determination of rock strength from cutting tests. Master's thesis 1999, University of Minnesota, USA.

[54] Kaitkay P, Lei S. Experimental study of rock cutting under external hydrostatic pressure. J Mater Process Technol 2005; 159(2): 206-213.

[55] Garcia-Gavito D. Cutting mechanics modeling for polycrystalline diamond compacts and extension to the drill bit. Ph.D. Thesis1998, University of Tulsa, USA.

[56] Menezes PL, Lovell MR. Influence of rock mechanical properties on the formation of rock fragments during cutting operation. ASME/STLE International Joint Tribology Conference 2011; Los Angeles, USA, 253-255.

[57] Menezes PL, Lovell MR, Higgs CF III. Influence of friction and rake angle on the formation of discontinuous rock fragments during rock cutting. STLE/ASME International Joint Tribology Conference 2010; San Francisco, USA, 2010, 271-273. 


\section{Figure Captions}

Fig. 1: (a) Rock cutting simulation and (b) Variation of cutting forces with distance for sandstone rock slab when rake angle is $+15^{\circ}$

Fig. 2: Cutting simulation of sandstone rock for a cutting depth of $3 \mathrm{~mm}$ and $+15^{\circ}$ rake angle when (a) velocity $=0.1 \mathrm{~mm} / \mathrm{s}$ and (b) velocity $=100 \mathrm{~mm} / \mathrm{s}$.

Fig. 3: (a) Variation of cutting forces with velocity for various depths of cut (b) Variation of cutting forces with depth of cut for various velocities.

Fig. 4: Cutting simulation of sandstone rock for $0^{\circ}$ rake angle at a cutting depth of $1 \mathrm{~mm}$ and velocity of $100 \mathrm{~mm} / \mathrm{s}$.

Fig. 5: Cutting simulation of sandstone rock for a cutting depth of $3 \mathrm{~mm}$ and $0^{\circ}$ rake angle when (a) velocity $=0.1 \mathrm{~mm} / \mathrm{s}$ and (b) velocity $=100 \mathrm{~mm} / \mathrm{s}$.

Fig. 6: (a) Variation of cutting forces with velocity for various depths of cut (b) Variation of cutting forces with depth of cut for various velocities.

Fig. 7: Cutting simulation of sandstone rock for $-15^{\circ}$ rake angle at a cutting depth of 1 $\mathrm{mm}$ and velocity of $100 \mathrm{~mm} / \mathrm{s}$.

Fig. 8: Cutting simulation of sandstone rock for a cutting depth of $3 \mathrm{~mm}$ and $-15^{\circ}$ rake angle when (a) velocity $=0.1 \mathrm{~mm} / \mathrm{s}$ and (b) velocity $=100 \mathrm{~mm} / \mathrm{s}$.

Fig. 9: (a) Variation of cutting forces with velocity for various depths of cut (b) Variation of cutting forces with depth of cut for various velocities.

Fig. 10: Cutting simulation of limestone rock for (a) $+15^{\circ}$ (b) $0^{\circ}$ and (c) $-15^{\circ}$ rake angles for a cutting depth of $1 \mathrm{~mm}$ and cutting velocity of $100 \mathrm{~mm} / \mathrm{s}$.

Fig. 11: Variation of cutting forces with depth of cut at different velocities for $(a)+15^{\circ}$ (b) $0^{\circ}$ and (c) $-15^{\circ}$ of rake angles when simulations are performed using limestone rock slab. 
(a)

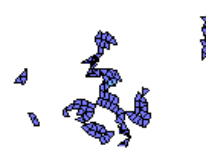

Effective Stress (GPa)

2.000e-01

1.800e-01

1.600e-01

Rake Angle $=+15^{\circ}$

Velocity $=100 \mathrm{~mm} / \mathrm{s}$

Depth of Cut $=1 \mathrm{~mm}$

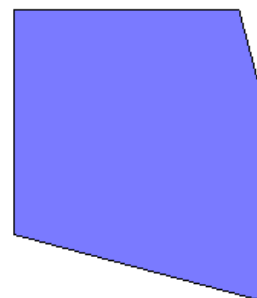

$1.400 \mathrm{e}-01$

1.200e-01

1.000e-01

8.000e-02

$6.000 \mathrm{e}-02$

4.000e-02

$2.000 \mathrm{e}-02$
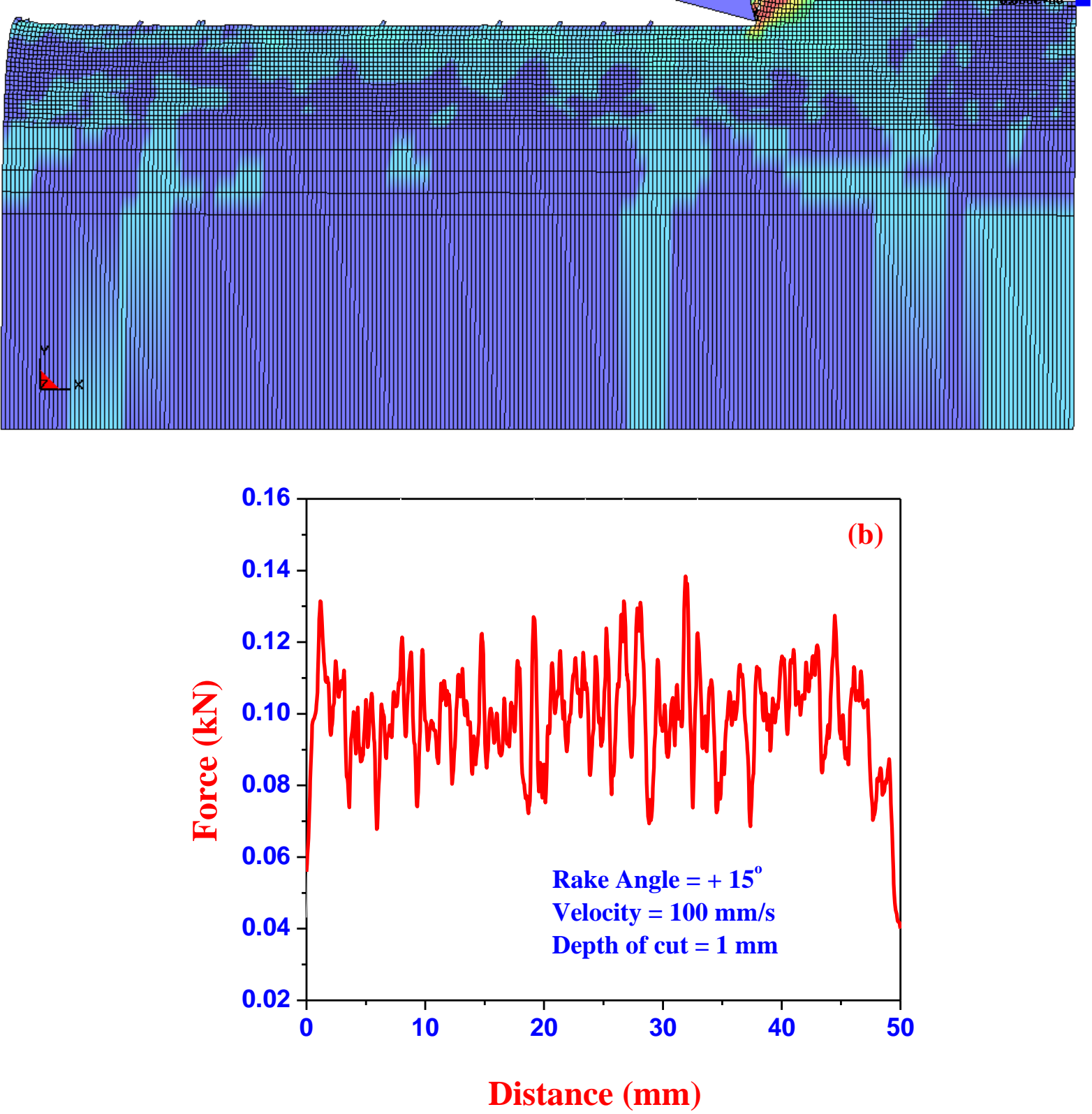

Fig. 1: (a) Rock cutting simulation and (b) Variation of cutting forces with distance for sandstone rock slab when rake angle is $+15^{\circ}$ 
(a)

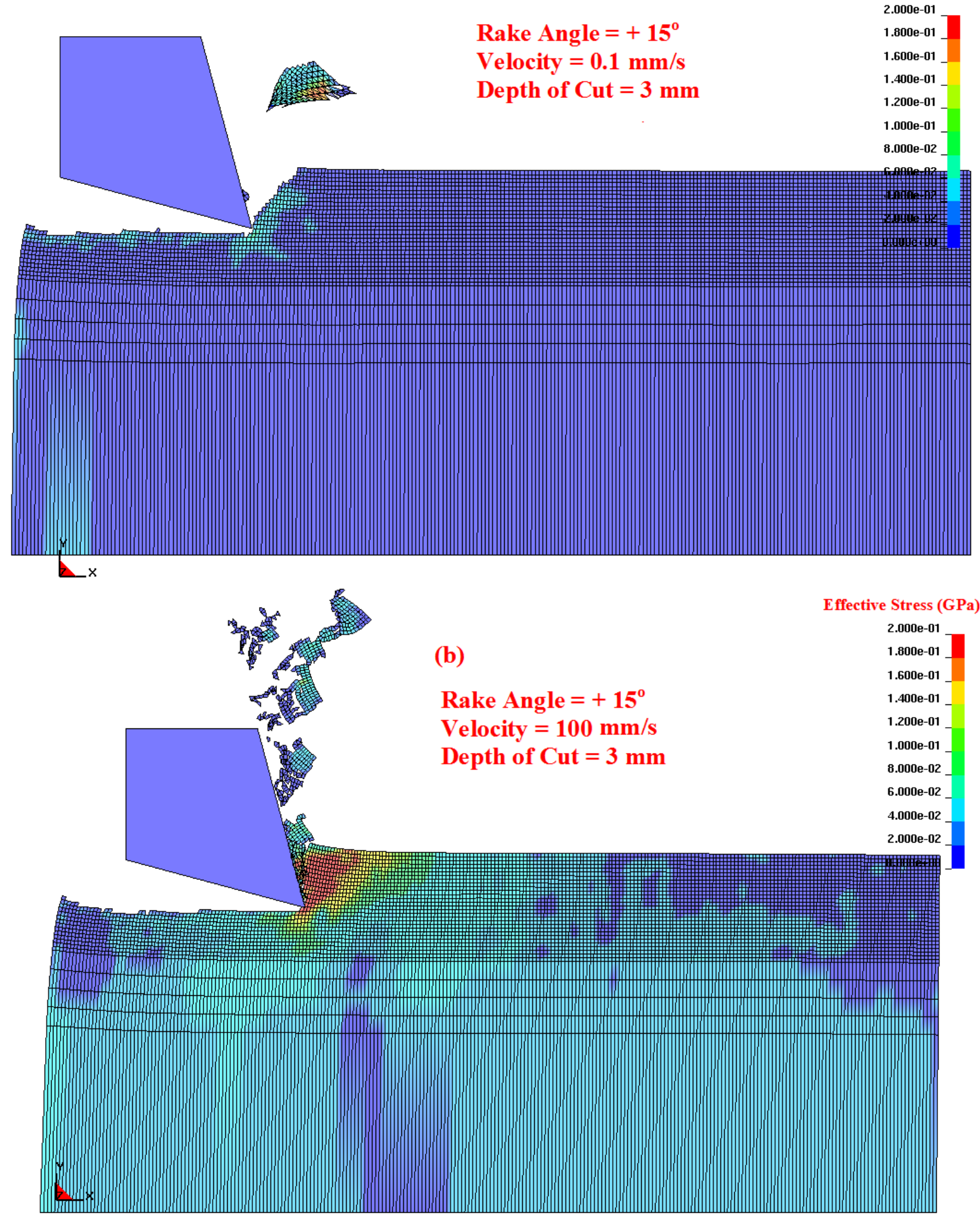

Fig. 2: Cutting simulation of sandstone rock for a cutting depth of $3 \mathrm{~mm}$ and $+15^{\circ}$ rake angle when (a) velocity $=0.1 \mathrm{~mm} / \mathrm{s}$ and (b) velocity $=100 \mathrm{~mm} / \mathrm{s}$. 

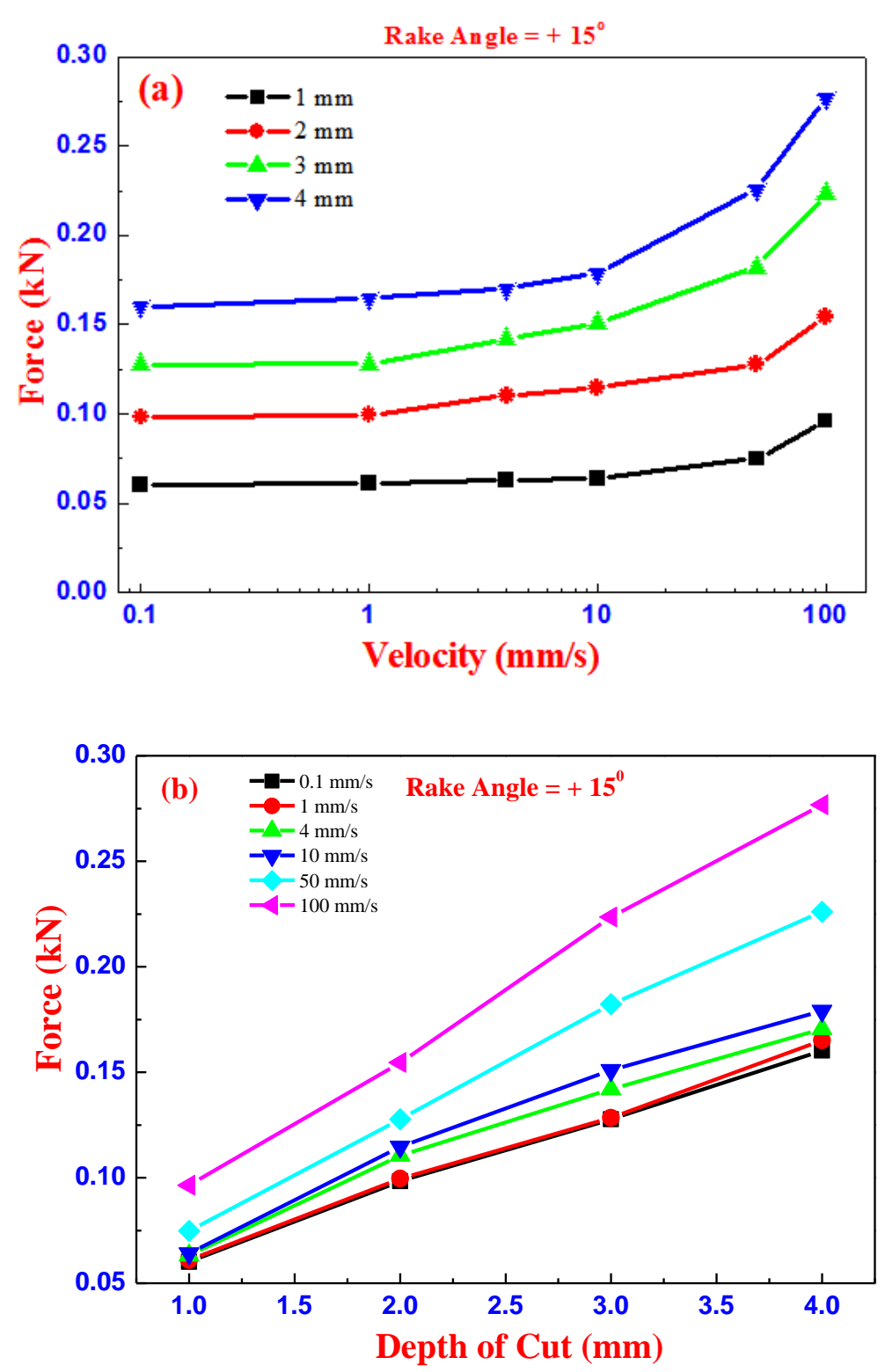

Fig. 3: (a) Variation of cutting forces with velocity for various depths of cut (b) Variation of cutting forces with depth of cut for various velocities. 


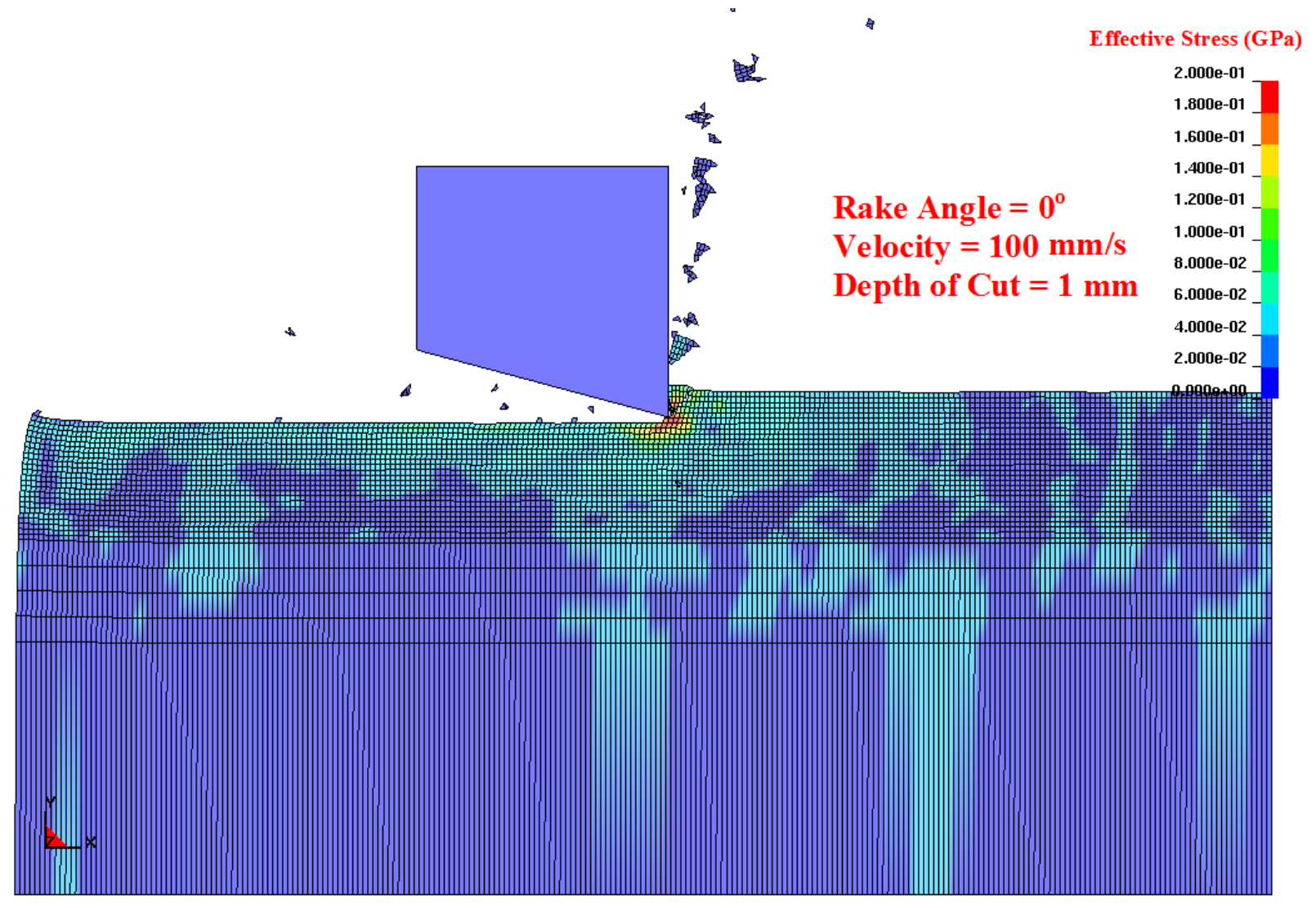

Fig. 4: Cutting simulation of sandstone rock for $0^{\circ}$ rake angle at a cutting depth of $1 \mathrm{~mm}$ and velocity of $100 \mathrm{~mm} / \mathrm{s}$. 
Effective Stress (GPa)

(a)

Rake Angle $=0^{\circ}$

Velocity $=0.1 \mathrm{~mm} / \mathrm{s}$

Depth of Cut $=3 \mathrm{~mm}$

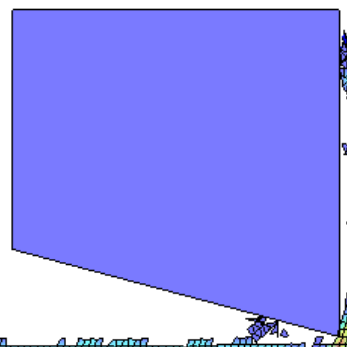

2.000e-01

1.800e-01

$1.600 \mathrm{e}-01$

1.400e-01

1.200e-01

1.000e-01

8.000e-02

$6.000 \mathrm{e}-02$
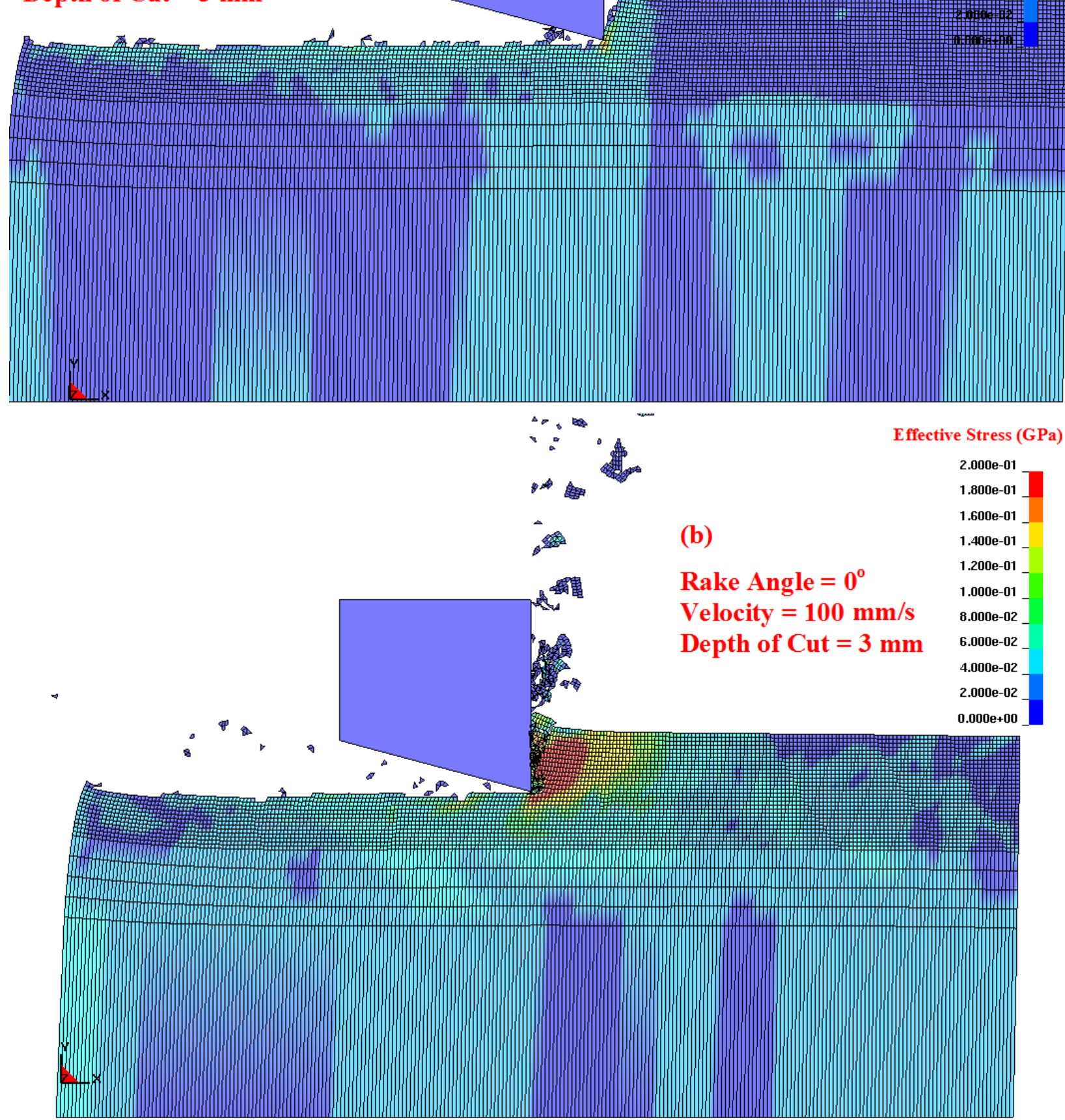

Effective Stress (GPa)

Fig. 5: Cutting simulation of sandstone rock for a cutting depth of $3 \mathrm{~mm}$ and $0^{\circ}$ rake angle when (a) velocity $=0.1 \mathrm{~mm} / \mathrm{s}$ and (b) velocity $=100 \mathrm{~mm} / \mathrm{s}$. 

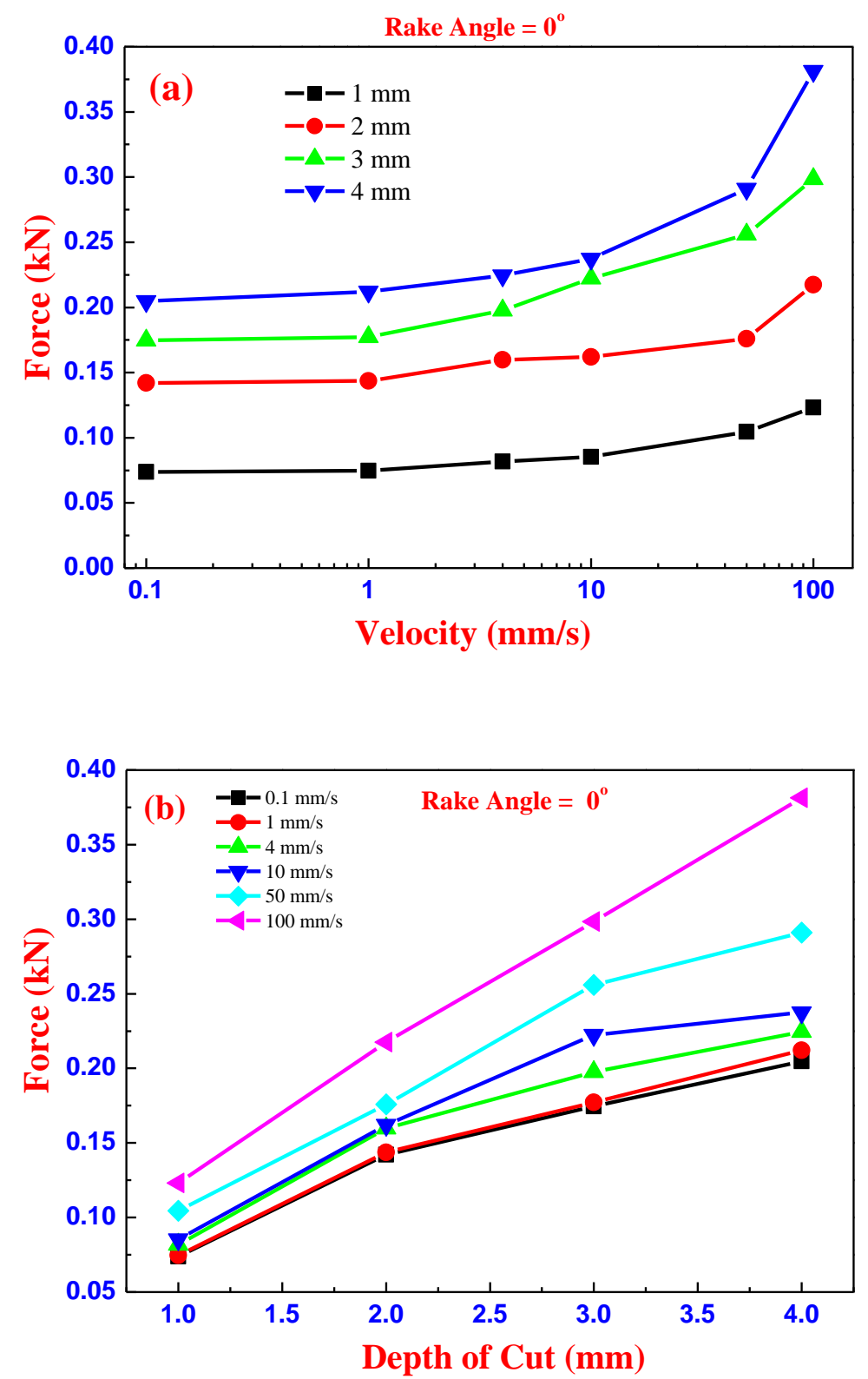

Fig. 6: (a) Variation of cutting forces with velocity for various depths of cut (b) Variation of cutting forces with depth of cut for various velocities. 


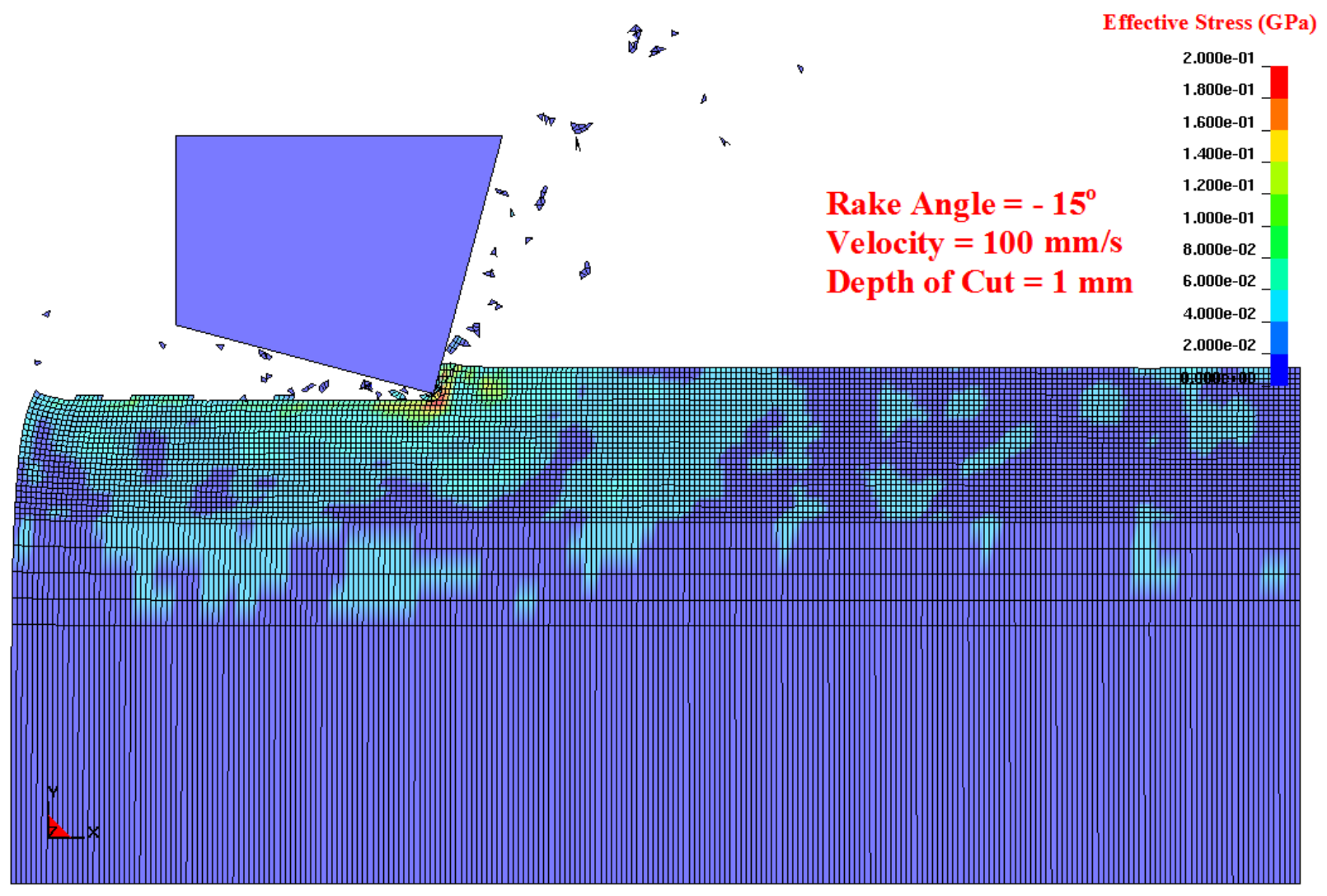

Fig. 7: Cutting simulation of sandstone rock for $-15^{\circ}$ rake angle at a cutting depth of $1 \mathrm{~mm}$ and velocity of $100 \mathrm{~mm} / \mathrm{s}$. 


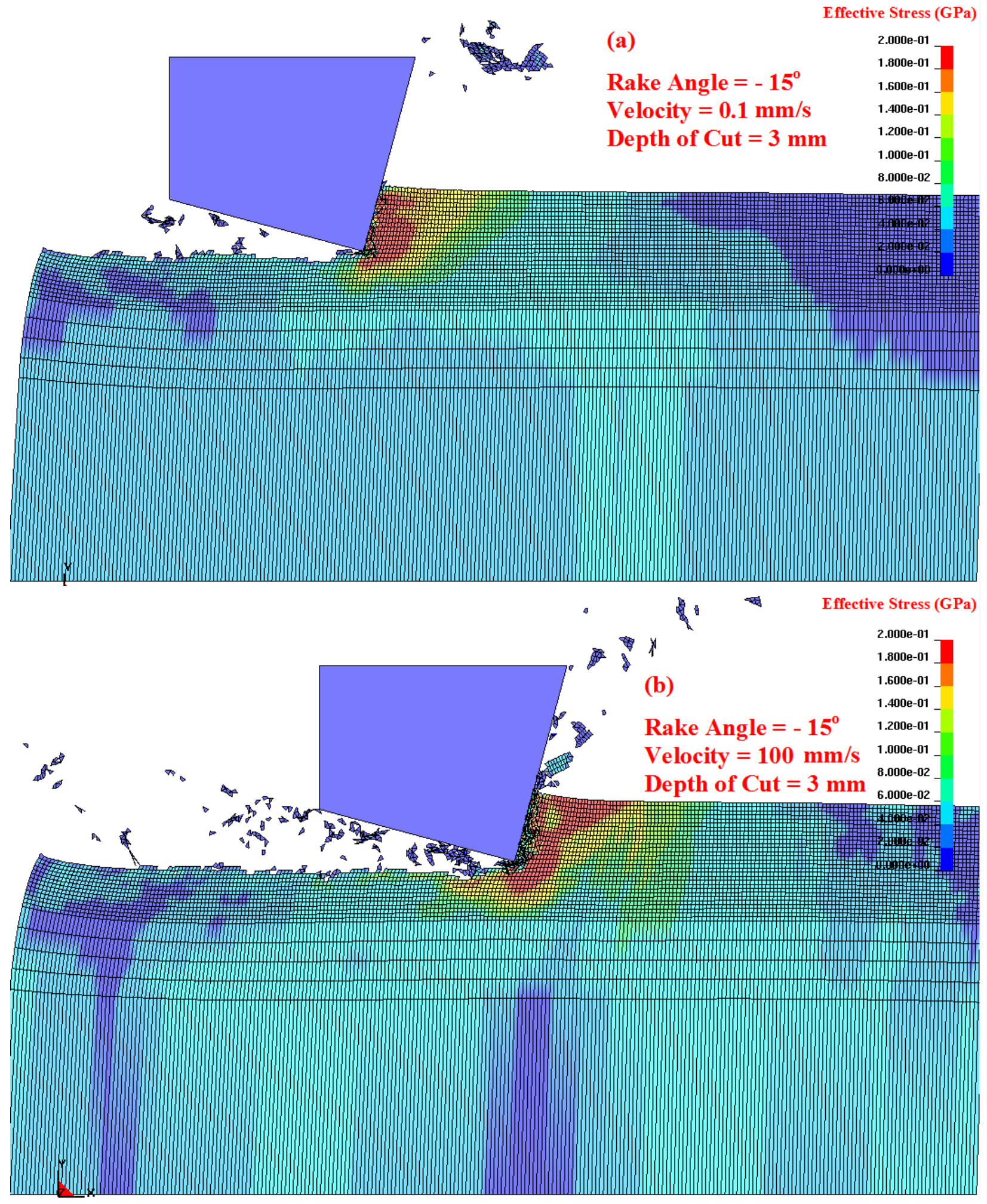

Fig. 8: Cutting simulation of sandstone rock for a cutting depth of $3 \mathrm{~mm}$ and $-15^{\circ}$ rake angle when (a) velocity $=0.1 \mathrm{~mm} / \mathrm{s}$ and (b) velocity $=100 \mathrm{~mm} / \mathrm{s}$. 

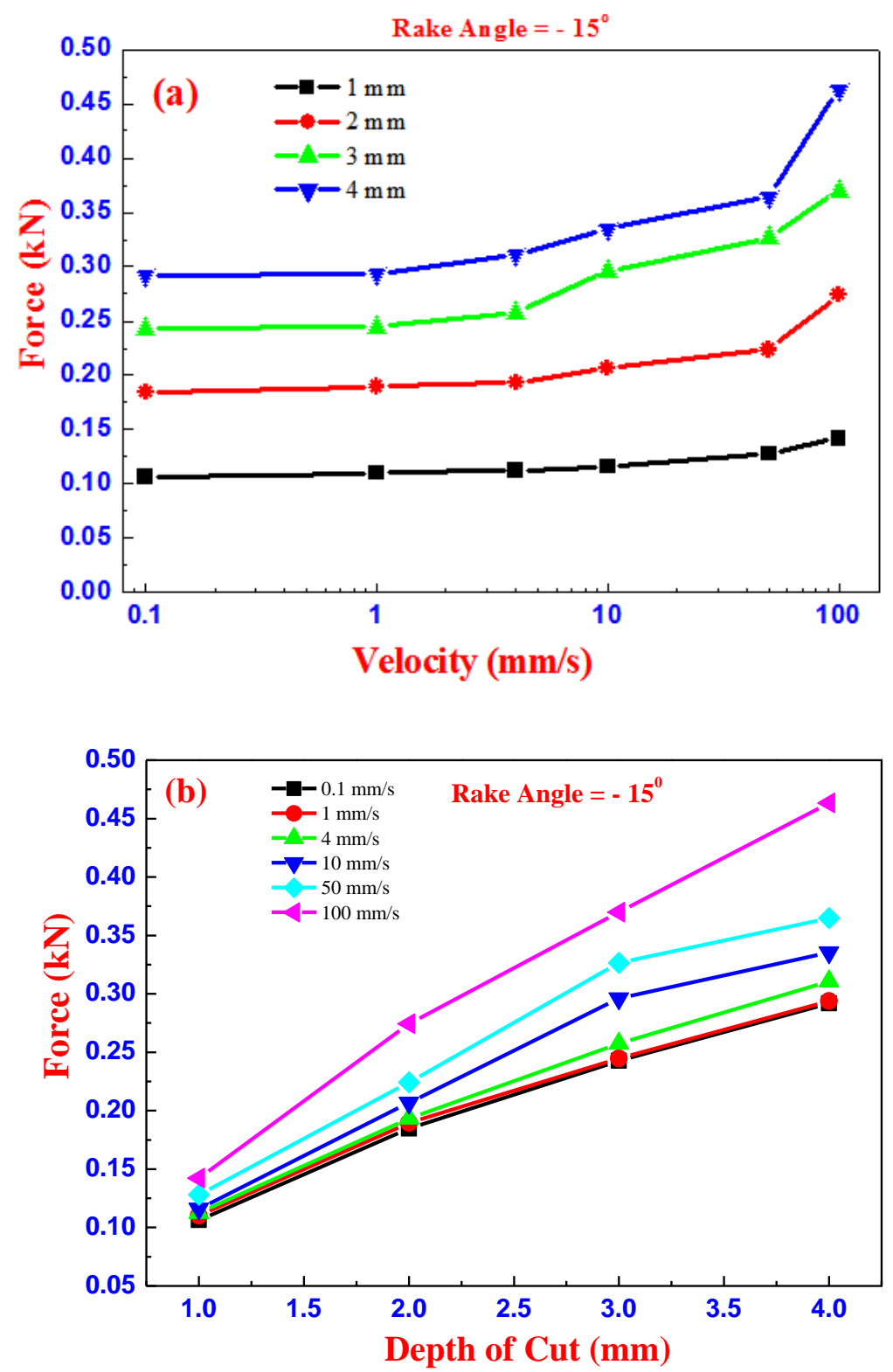

Fig. 9: (a) Variation of cutting forces with velocity for various depths of cut (b) Variation of cutting forces with depth of cut for various velocities. 


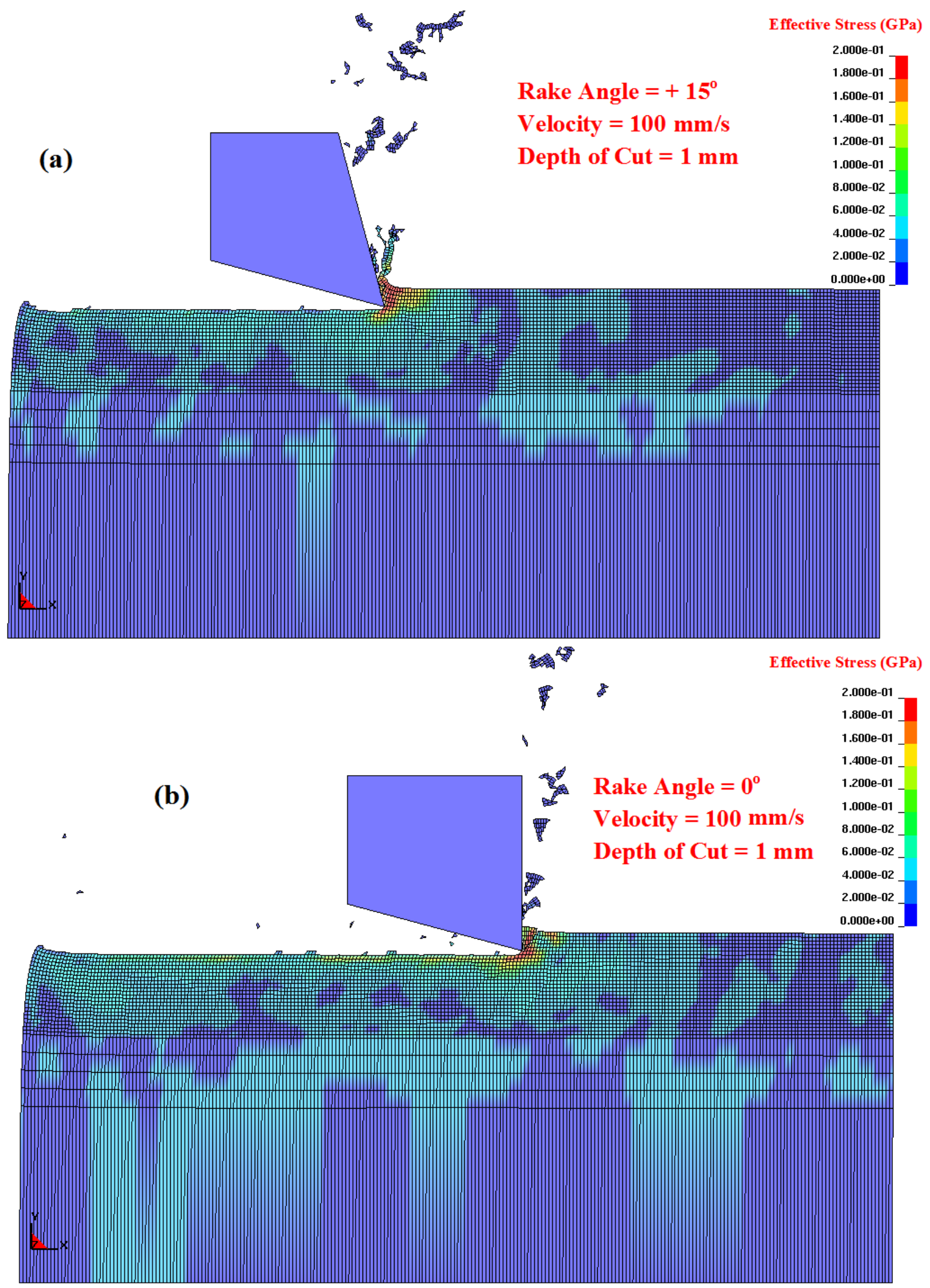




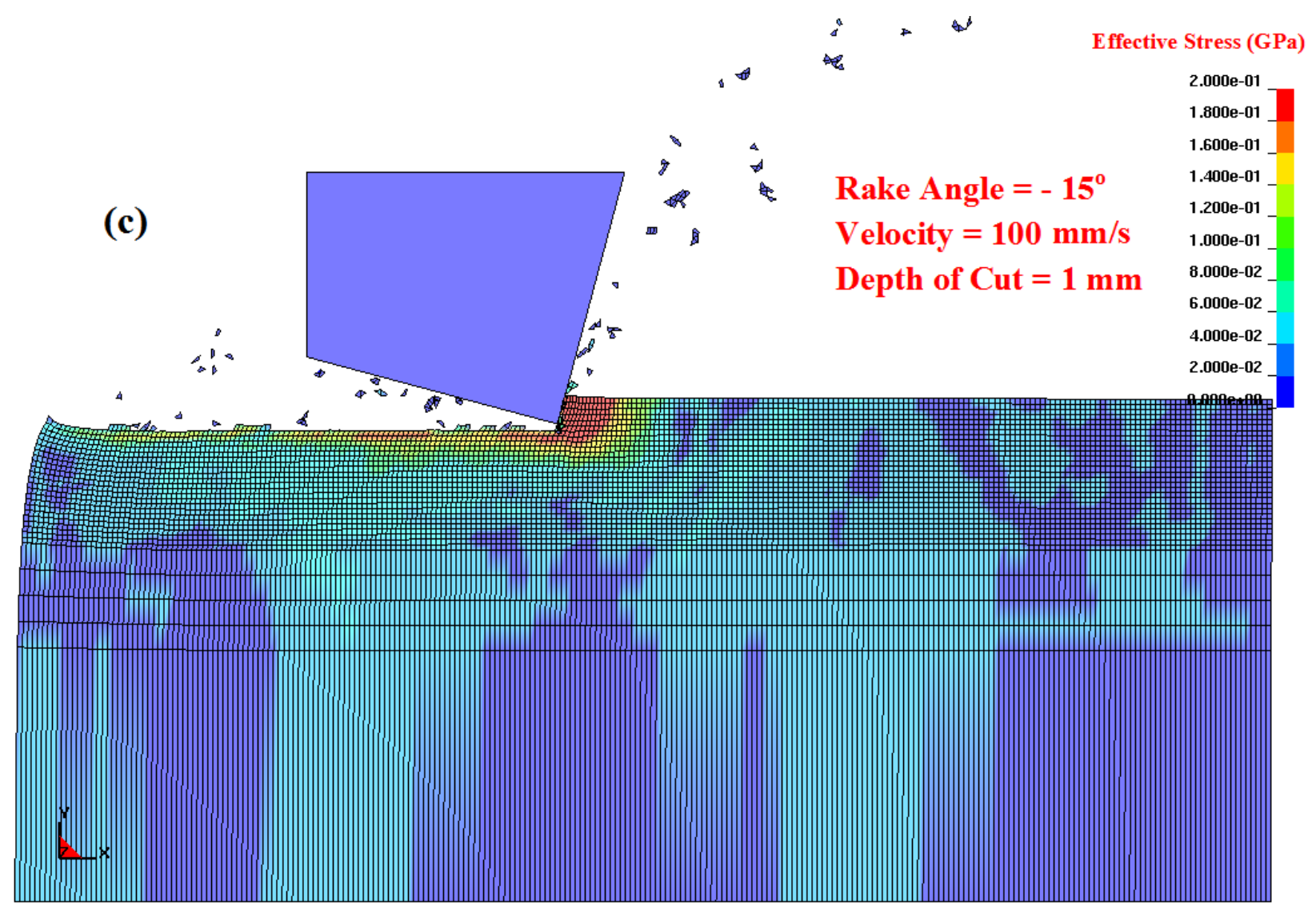

Fig. 10: Cutting simulation of limestone rock for (a) $+15^{\circ}$ (b) $0^{\circ}$ and (c) $-15^{\circ}$ rake angles for a cutting depth of $1 \mathrm{~mm}$ and cutting velocity of $100 \mathrm{~mm} / \mathrm{s}$. 

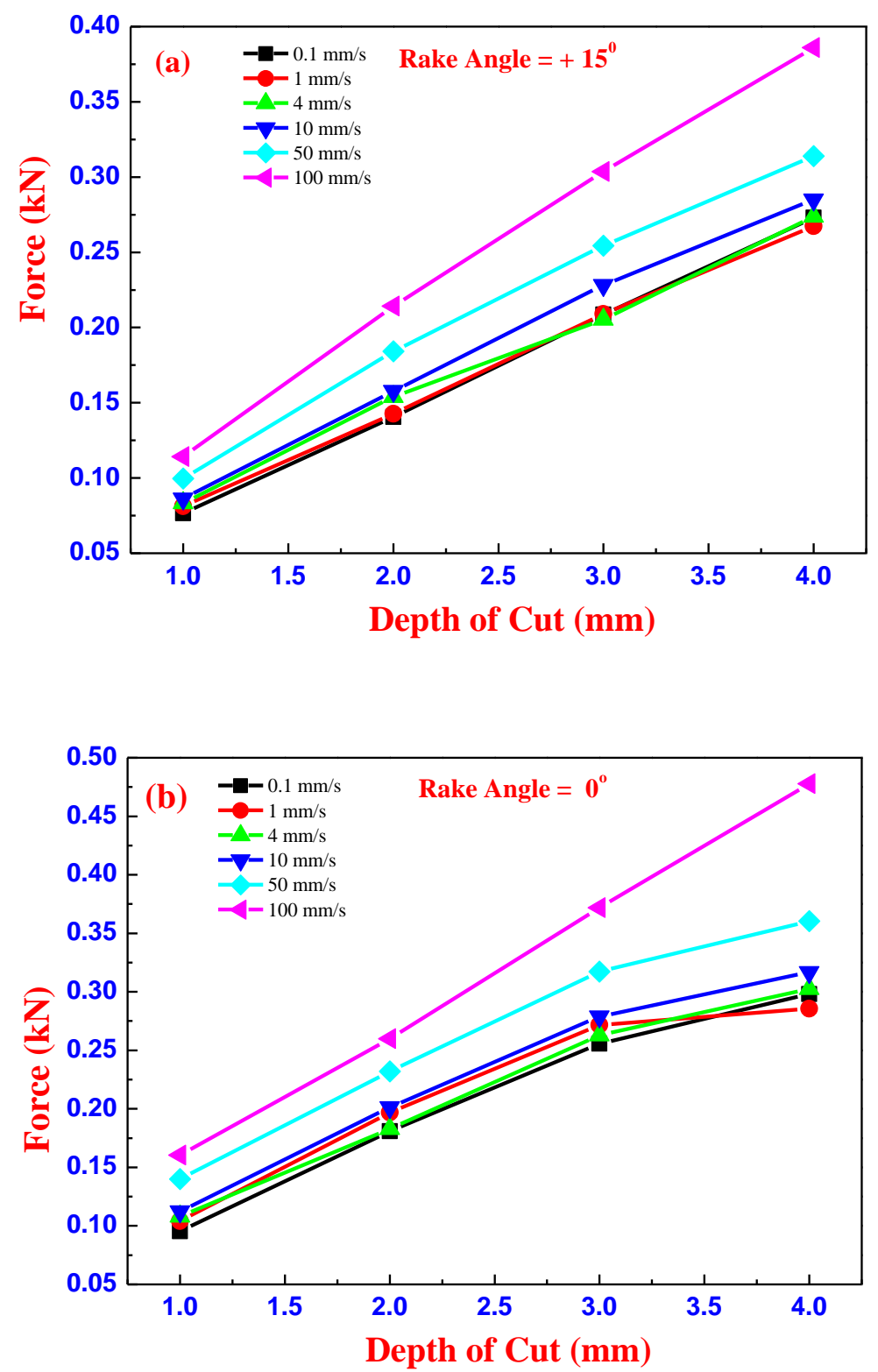


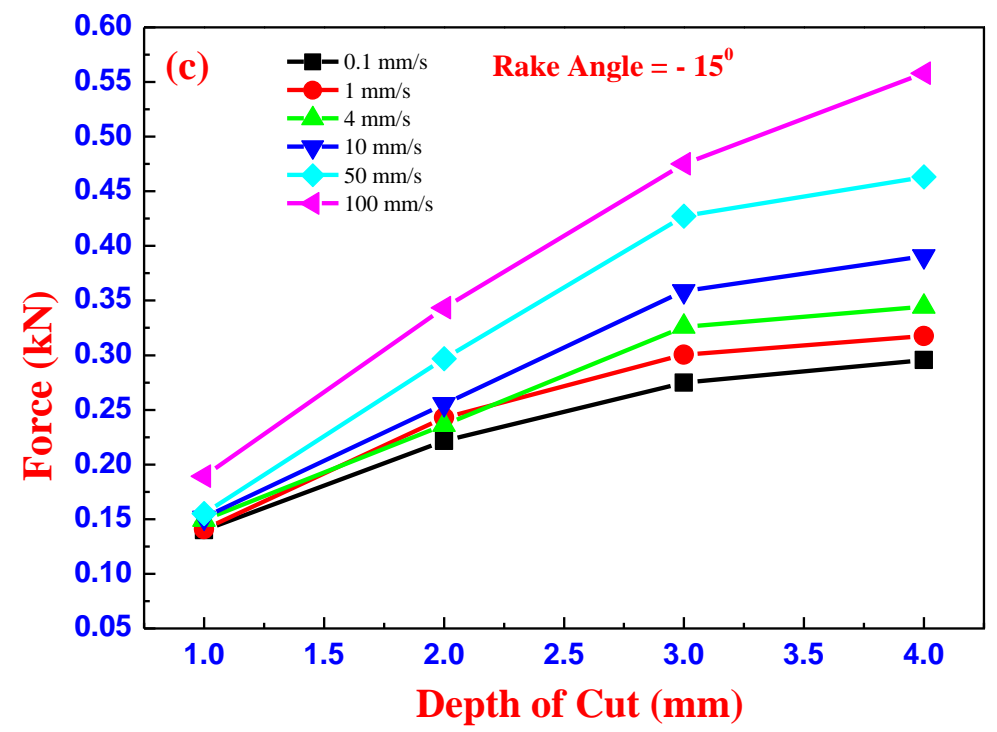

Fig. 11: Variation of cutting forces with depth of cut at different velocities for (a) $+15^{\circ}$ (b) $0^{\circ}$ and (c) $-15^{\circ}$ of rake angles when simulations are performed using limestone rock slab. 
Table 1: Properties of tool and rock materials [42]

\begin{tabular}{|l|l|l|l|l|}
\hline & Materials & $\begin{array}{l}\text { Density } \\
\left.(\rho) \mathrm{kg} / \mathrm{m}^{3}\right)\end{array}$ & $\begin{array}{l}\text { Young's modulus } \\
(E)(\mathrm{GPa})\end{array}$ & $\begin{array}{l}\text { Poisson's } \\
\text { ratio }(v)\end{array}$ \\
\hline Cutting tool & Steel & 7830 & 210 & 0.30 \\
\hline $\begin{array}{l}\text { Base rock } \\
\text { slab }\end{array}$ & Sandstone & 2000 & 7.453 & 0.33 \\
\cline { 2 - 5 } & Limestone & 2700 & 15 & 0.20 \\
\hline
\end{tabular}

Table 2: Input damage parameters for Mat_105

\begin{tabular}{|l|c|}
\hline \multicolumn{1}{|c|}{ Damage Parameters } & Values \\
\hline Damage threshold $\left(\mathrm{r}_{\mathrm{D}}\right)$ & 0.003 \\
\hline Damage Strength $(\mathrm{S})$ & 1.0 \\
\hline Critical damage value $\left(\mathrm{D}_{\mathrm{c}}\right)$ & $1.0 \times 10^{-3}$ \\
\hline
\end{tabular}

